\title{
CORRELAÇÕES ENTRE CARACTERÍSTICAS MORFOLÓGICAS E PRODUTIVAS EM BANANEIRA 'PRATA-ANÃ'
}

\author{
Correlations between vegetative and productive characteristics in banana 'Prata-anã'
}

\author{
José Egídio Flori , João Alexio Scarpare Filho², Geraldo Milanez de Resende \\ Carlos Alberto Tuão Gava ${ }^{1}$
}

\begin{abstract}
RESUMO
O objetivo deste trabalho foi avaliar algumas correlações entre as características da planta em bananeira 'Prata-Anã' grupo genômico (AAB) conduzidas de uma forma diferente da tradicional e em diferentes épocas no período de fevereiro de 2002 a janeiro de 2003. O experimento foi instalado na Fazenda Reunidas FLL Ltda em uma área cultivada com a cultura da bananeira com cinco anos de idade e plantadas no espaçamento de 3,5 m x 2,0 m, no município de Cristais Paulista-SP. O delineamento estatístico utilizado foi inteiramente casualizado no esquema de parcelas subdivididas, com três repetições, sendo as parcelas constituídas pelos tipos de manejos $\left(\mathrm{M}_{1}\right)$ - planta-filha desenvolvida sem a planta-mãe, a qual teve o pseudocaule retirado logo após a emissão floral e $\left(\mathrm{M}_{2}\right)$ planta-filha e planta-mãe desenvolvidas normalmente até a colheita de seus cachos (manejo convencional). As subparcelas foram constituídas por doze épocas de seleção da planta-filha (fev./02 a jan./03). Avaliou-se as características circunferência do pseudocaule, peso do cacho das plantas-mãe e filhas e o ciclo vegetativo da planta-filha. De acordo com as análises das variáveis avaliadas, observou-se correlação positiva entre as circunferências dos pseudacaules das plantas-mãe e plantas-filha, correlação positiva entre a circunferência do pseudocaule da planta-mãe e o peso do seu cacho, porém esta correlação não foi significativa na planta-filha, os pesos dos cachos das plantas-mãe e plantas-filha não foram correlacionados entre si, o ciclo vegetativo das plantas-filha correlacionouse negativamente com a circunferência do pseudocaule das mesmas e os manejos nas touceiras $\left(M_{1}\right)$ e $\left(M_{2}\right)$ e as épocas de seleção da planta-filha não afetaram as correlações avaliadas neste trabalho.
\end{abstract}

Termos para indexação: Musa ssp (AAB), programação de colheita, pseudocaule.

\begin{abstract}
The aim of this study was to evaluate the correlations between vegetative and productive characteristics of banana tree (Musa spp) cv 'Prata-Anã' (genomic group AAB) differently managed from the conventional system. The experiment was carried out in an orchard with five years old banana plants spaced by 3,5 x 2,0 m, in the Fazendas Reunidas FFL Ltda., at Cristais Paulista, São Paulo, Brazil. The experiment was a split plot under a completely randomized design with three replicates, being the main treatments constituted by: $M_{1}$ - daughter-plant without the mother-plant whose stem was cut after flowering; $M_{2}$ - daughter-plant and motherplant conventionally managed until harvest. The sub plots were constituted by twelve periods of selection of the daughter-plants (February 2002 to January 2003). The pseudostem diameter and the bunch weight of all plants and the vegetative period of the daughter-plants were evaluated. The statistical analysis showed a positive correlation between the stem diameter of the daughterplants and mother-plants. The stem diameter of the mother-plant was positive correlated with its bunch weight. However the stem diameter of the daughter-plant not was correlated with its bunch weight. The vegetative cycle and the pseudostem diameter of the daughter-plants were negatively correlated. The Plant management $\left(\mathrm{M}_{1}\right.$ and $\left.\mathrm{M}_{2}\right)$ and the selection of periods daughter-plant did not affected the correlations evaluated in this study.
\end{abstract}

Index terms: Musa spp. pseudostem, vegetative cycle, bunch weight.

(Recebido para publicação em 20 de setembro de 2005 e aprovado em 12 de maio de 2006)

\section{INTRODUÇÃO}

O cultivo da bananeira desenvolve-se preferencialmente em climas tropicais com boa disponibilidade hídrica e temperaturas variando de $15^{\circ} \mathrm{C}$ a $35^{\circ} \mathrm{C}$, sendo as temperaturas ideais de crescimento de $18^{\circ} \mathrm{C}$ à noite e $25^{\circ} \mathrm{C}$ durante o dia (MOREIRA, 1999). As condições climáticas favoráveis ao crescimento da bananeira são normalmente encontradas na faixa compreendida entre os paralelos de $30^{\circ}$ de latitude norte e $30^{\circ}$ de latitude sul, desde que nestas regiões as temperaturas situem entre os limites de $10^{\circ}$ a $40^{\circ}$ (SOTOBALLESTERO, 1992). Entretanto, segundo Alves (1999) e Moreira (1999), existe a possibilidade de seu cultivo em latitudes acima de $30^{\circ}$, desde que a temperatura fique entre os limites citados.

Os fatores abióticos que mais afetam o crescimento da bananeira e que não podem ser alterados diretamente pelo homem são: luz e temperatura. Entretanto, a luz incidente no território brasileiro, cujas latitudes variam de $4^{\circ}$ norte $\mathrm{e}$

'Engenheiro Agrônomo, PhD, Agronomia/Fitotecnia - Pesquisador da Embrapa Semi-Arido - Rod. BR 428, Km 152 s/n - Zona Rural - Cx. P. 023 56300-970 - Petrolina, PE.

${ }^{2}$ Engenheiro Agrônomo, PhD, Professor da ESALQ/USP - Cx. P. 11 - 13418-900 - Piracicaba, SP. 
$30^{\circ}$ sul, na maior parte dos dias de verão sem nuvem, satisfaz os níveis de radiação para a fotossíntese máxima da cultura de bananeira $\left(0,3\right.$ a $0,8 \mathrm{cal} \mathrm{cm}^{-2} \mathrm{~min}^{-1}$ ou $209 \mathrm{~W} \mathrm{~m}$ ${ }^{2}$ a $557 \mathrm{~W} \mathrm{~m}^{-2}$ )(FAO, 1993; SENTELHAS et al., 2000).

Simmonds (1964) relata que nas fases preliminares do estudo de plantas normalmente é baseado em pesquisa de estudo de correlações.

Ledo et al. (2002) se valeram do estudo de correlação entre caracteres do cacho para predizer a produção de frutos em bananeira 'Prata anã' do subgrupo Prata. Blomme et al. (2003), trabalhando com um genótipo de Musa spp. AAB, encontraram correlação positiva entre o peso do cacho e as características altura da planta, peso fresco do rizoma, número de raízes, comprimento das raízes primárias e comprimento das raízes secundárias.

Segundo Soto-Ballestero (1992), a atividade fisiológica da planta-filha correlaciona-se com a plantamãe, mas isto acontece aparentemente até a planta-filha emitir as primeiras 7,5 a 12,5 folhas iniciais e quando a lâmina foliar, medida transversalmente na metade do seu comprimento, atingir cerca de $10 \mathrm{~cm}$ de largura. Segundo Lassoudiérie (1978, 1979), citado por Soto-Ballestero (1992), a independência da planta-filha ocorre quando a primeira folha característica "Fm" do clone for emitida, isto normalmente ocorrerá depois da emissão média das primeiras 20 folhas, a retirada da planta-mãe antes que a planta-filha atinja o referido estádio poderá prejudicar a produção da sua filha.

Na bananeira 'Prata anã' o acompanhamento do crescimento do pseudocaule dá uma boa idéia do crescimento como um todo da planta, já que o mesmo representa juntamente com outras partes da folha (pecíolo e limbo) mais de $2 / 3$ de toda planta (BELALCÁZARCARVAJAL, 1991; BORGES, 2000; GOMES, 1988; MANICA, 1997).

Na maioria dos estudos de correlação, o diâmetro do pseudocaule é a característica morfológica que apresenta o maior valor de correlação positiva com o peso do cacho (SIMMONDS, 1964; SIQUEIRA, 1984). Siqueira (1984) encontrou também alta correlação positiva entre o peso do cacho e o número de folhas ativas na colheita de sete clones de bananeira 'Prata' do subgrupo Prata.

Buscou-se com este trabalho, verificar as correlações entre as características morfológicas e produtivas em plantas de bananeira 'Prata-Anã' Musa ssp. (AAB).

\section{MATERIAL E MÉTODOS}

O trabalho foi realizado na Fazenda Reunidas FLL Ltda, localizada no Município de Cristais Paulista - SP, situada nas coordenadas geográficas de $20^{\circ} 22^{\prime} 42^{\prime \prime}$ de Latitude sul e de $47^{\circ} 29^{\prime} 36^{\prime \prime}$ de Longitude oeste e com altitude de $918 \mathrm{~m}$. O solo foi caracterizado como sendo do tipo Latossolo de textura média e a topografia do local com pequena declividade. As temperaturas médias mensais e a distribuição de chuva do local do experimento podem ser verificadas na Figura 1. Foi utilizada a cultivar 'Prata-Anã', grupo genômico AAB, plantada no espaçamento de 3,5 m x 2,0 m, em 1997.

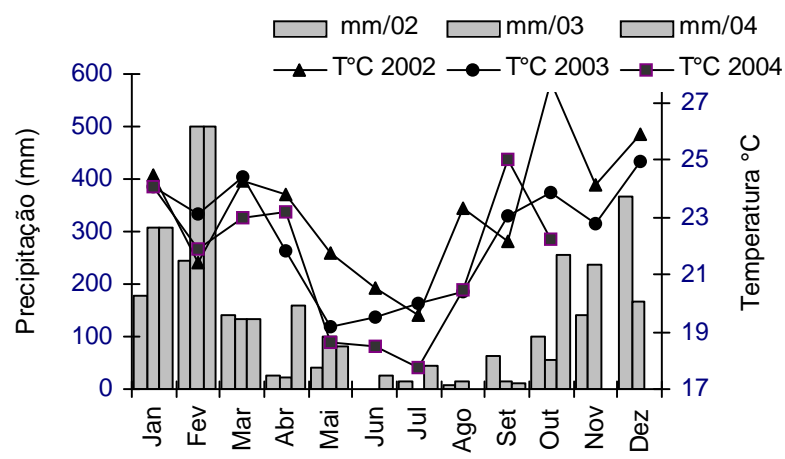

FIGURA 1 -Precipitação mensal (mm) e temperatura média mensal na Fazenda Reunidas RLL Ltda, no período de jan./2002 até dez./2004. Franca, SP, 2004.

A área experimental foi demarcada em fevereiro de 2002, numa área total de 2,1 hectares. O delineamento estatístico utilizado foi o inteiramente casualizado, com três repetições. Os tratamentos foram dispostos no esquema de parcelas subdivididas. Nas parcelas foram testados o manejo da planta-mãe, sendo o manejo $1\left(\mathrm{M}_{1}\right)$ - touceira em que a planta-mãe foi retirada imediatamente após sua floração e a planta-filha desenvolveu-se sem a planta-mãe e o manejo $2\left(\mathrm{M}_{2}\right)$ - touceira na qual a planta-mãe e a planta-filha desenvolveram-se normalmente (manejo realizado pelos produtores). Os tratamentos nas subparcelas constituíram de doze épocas de seleção da planta-filha. Cada subparcela continha cinco plantas (touceiras). As épocas tiveram intervalos mensais sendo representadas pelos meses do ano. A escolha das famílias ou touceiras selecionadas apresentavam as plantas-mãe com o cacho recém emitido e uma planta-filha no estádio de chifrão tendo em média $0,15 \mathrm{~m}$ de circunferência do pseudocaule, medido a $1 \mathrm{~m}$ de altura do solo, e 1,5 m de altura. Para cada período de 30 dias consecutivos foram selecionadas 30 famílias na condição descrita acima, das quais 15 famílias tiveram os cachos e os pseudocaules das plantas-mãe cortados $\left(\mathrm{M}_{1}\right)$ e 15 famílias foram conduzidas mantendo-se as 
plantas-mãe até a colheita $\left(\mathrm{M}_{2}\right)$. A primeira época de seleção foi em fev./02 e a última em jan./03. As características avaliadas foram circunferência do pseudocaule da planta-mãe (CPM) e da planta-filha (CPF), medidas a $1 \mathrm{~m}$ de altura do solo, peso dos cachos da planta-mãe (PCM) e da planta-filha (PCF), ciclo vegetativo da planta-filha (CCC) (período em dias, decorridos entre a marcação da planta-filha no estádio chifrão até a sua colheita). As circunferências do pseudocaule das plantasmãe foram tomadas na floração a partir de fev./02 até jan./ 03 e esta variável foi medida nas plantas-filha à medida que as mesmas floresciam. A tomada dos dados do ciclo vegetativo das plantas-filha iniciou-se a partir de fev./02 (primeira época de seleção) e finalizou em dez./04 (colheitas das plantas-filha selecionadas em jan./03 última época de seleção). O peso do cacho foi tomado no ponto ideal de colheita (queda dos pistilos e quinas dos frutos pouco proeminentes).

Com os dados obtidos foram calculadas as correlações entre a circunferência do pseudocaule da planta-mãe versus a circunferência do pseudocaule de sua filha; o ciclo vegetativo da planta-filha versus a circunferência do seu pseudocaule; o peso do cacho da planta-mãe versus peso do cacho da sua filha e a circunferência do pseudocaule da planta-mãe e filha versus a peso do cacho das mesmas.

As análises estatísticas foram realizadas utilizando o sistema de análise estatística, SAS (SAS INSTITUTE, 1988).

\section{RESULTADOS E DISCUSSÃO}

Na Tabela 1, são apresentadas as correlações entre as características produtivas e morfológicas avaliadas. Constatou-se a correlação positiva entre as circunferências dos pseudocaules entre plantas-mãe (CPM) e suas respectivas plantas-filha (CPF). A circunferência do pseudocaule da planta-filha correlacionou-se negativamente com o seu ciclo vegetativo (CCC). A correlação entre a circunferência do pseudocaule e o peso do cacho da planta-mãe (PCM) foi significativa e positiva e a mesma correlação não foi significativa na planta-filha (PCF). Não se observou correlação entre os pesos dos cachos das plantas-mãe e plantas-filha.

TABELA 1 - Estimativas do coeficiente de correlação (r) entre algumas características produtivas e morfológicas na bananeira 'Prata-Anã'. Cristais Paulista - SP, 2004.

\begin{tabular}{|c|c|c|c|c|c|}
\hline \multirow{2}{*}{ Características } & \multirow{2}{*}{$\begin{array}{l}\text { Tipo de } \\
\text { Manejo }\end{array}$} & \multicolumn{4}{|c|}{ Características } \\
\hline & & CPF & PCF & PCM & CCC* \\
\hline \multirow[t]{2}{*}{$\begin{array}{l}\text { Circunferência da planta-mãe } \\
\text { CPM }\end{array}$} & $\mathrm{M}_{1}$ & $0,50(0,002)$ & $-0,02(0,921)$ & -- & -- \\
\hline & $\mathrm{M}_{2}$ & $0,56(0,001)$ & $-0,25(0,150)$ & $0,44(0,007)$ & -- \\
\hline \multirow[t]{2}{*}{$\begin{array}{l}\text { Circunferência da planta-filha } \\
\text { CPF }\end{array}$} & $\mathbf{M}_{1}$ & 1 & $0,09(0,611)$ & -- & $-0,41(0,014)$ \\
\hline & $\mathrm{M}_{2}$ & 1 & $-0,01(0,944)$ & -- & $-0,55(0,001)$ \\
\hline \multirow[t]{2}{*}{$\begin{array}{l}\text { Peso do cacho da filha } \\
\text { PCF }\end{array}$} & $\mathrm{M}_{1}$ & -- & 1 & -- & -- \\
\hline & $\mathrm{M}_{2}$ & -- & 1 & -- & -- \\
\hline $\begin{array}{l}\text { Peso do cacho da mãe } \\
\text { PCM }\end{array}$ & $\mathrm{M}_{2}$ & -- & $-0,25(0,140)$ & 1 & -- \\
\hline
\end{tabular}

(一) Indica o nível nominal de significância para $\mathrm{H}_{0}: \mathrm{r}=0$;

$\mathbf{M}_{1}$ - planta-filha desenvolvida sem a planta-mãe;

$\mathrm{M}_{2}$ - planta-filha desenvolvida na presença da mãe;

* - Ciclo vegetativo da planta-fillha no estádio chifrão até a colheita. 
A correlação entre as circunferências do pseudocaule das plantas-mãe e plantas-filha, tanto para o $\mathrm{M}_{1}$ como para o $\mathrm{M}_{2}$, apresentou magnitude média de $\mathrm{r}=0,50$ e $\mathrm{r}=0,56$, respectivamente, embora ambas foram altamente significativas (Figura 2). A correlação positiva entre as circunferências do pseudocaule das plantas-mãe e plantasfilha comprova uma relação fisiológica estreita entre ambas, sugerindo que parte do vigor da planta-mãe é compartilhado com a planta-filha.

Na Figura 3, são apresentadas as correspondências encontradas entre a circunferência do pseudocaule e o ciclo vegetativo em ambos manejos estudados. Nesse caso, observou-se que a correlação da circunferência do pseudocaule com o ciclo vegetativo foi negativa, isto indica que o vigor da planta, caracterizado neste caso pela circunferência da planta, afeta o ciclo vegetativo. Esse resultado indica que quanto maior a circunferência do pseudocaule da planta menor o ciclo vegetativo e vice-versa. Medindo-se esse efeito nas plantas avaliadas obteve-se uma diferença de 45 dias a menos no ciclo vegetativo das plantas-filha conduzidas sem a presença das mães $\left(M_{1}\right)$, as quais apresentavam uma circunferência média maior do que as circunferências das plantas-filha conduzidas na presença da planta-mãe $\left(\mathrm{M}_{2}\right)$, respectivamente de $81 \mathrm{~cm}$ e $78 \mathrm{~cm}$.

Uma possível utilização prática da correlação entre o ciclo vegetativo e a circunferência do pseudocaule e o ciclo vegetativo em função dos meses de seleção da plantafilha seria oferecer subsídios para direcionar a época de colheita (DEVALDENEBRO, 1984).

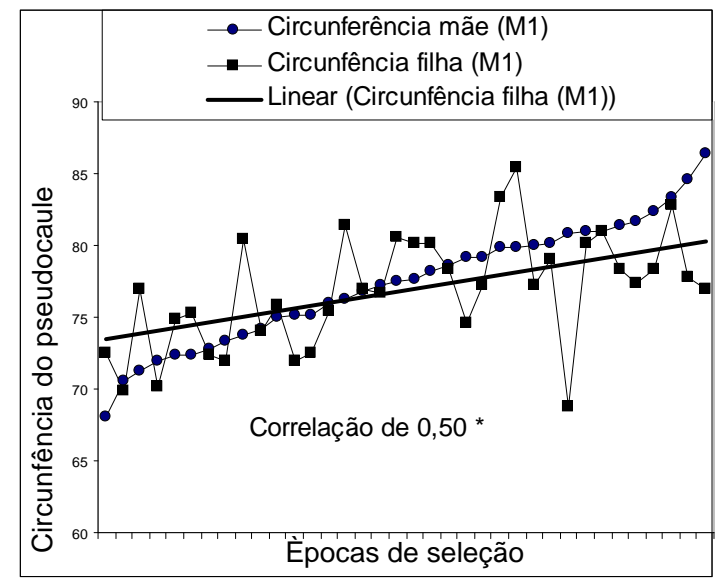

A correlação entre a circunferência da planta e o peso do seu cacho foi significativa e positiva quando são analisados os dados entre planta-mãe e seu cacho, já quando os dados referem-se a planta-filha e seu cacho a correlação não é significativa Tabela 1 . Nesse segundo caso a correlação da circunferência e o peso do cacho da planta-filha, em ambos os manejos, divergem dos resultados encontrados por Simmonds (1964) e Siqueira (1984), que observaram correlação positiva entre a circunferência do pseudocaule e a produção da planta. Siqueira (1984) verificou essa correlação positiva trabalhando com a cultivar 'Prata' do Sub grupo Prata e Simmonds (1964) com uma cultivar do Sub grupo Cavendish. A correlação não significativa entre a circunferência do pseudocaule e o peso do cacho da plantafilha faz crer que outros fatores podem afetar esta correlação.

Diante desses resultados sugere-se que novos estudos devem ser realizados no sentido de esclarecer melhor a correlação entre a circunferência do pseudocaule da planta e peso do cacho, tendo em vista ser um indicador importante para prever a produção antecipada, caso se confirme a correlação significativa entre essas características.

Não houve correlação entre os pesos do cacho da planta-mãe e da planta-filha.

O manejo da planta-mãe $\left(M_{1}\right)$ e $\left(M_{2}\right)$ e a época de seleção da planta-filha não afetaram de forma significativa as correlações estudadas.

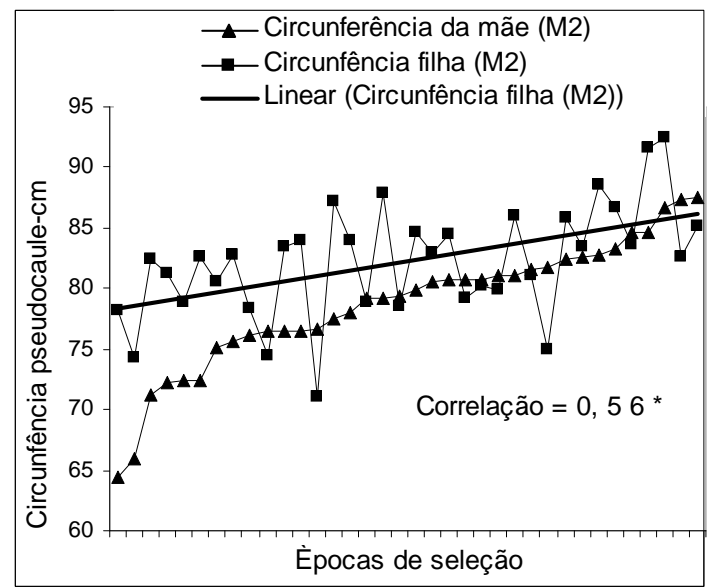

FIGURA 2 - Representação gráfica das correspondências entre as circunferências do pseudocaule das plantas-mãe e de suas filhas no manejo em que foi retirada a planta-mãe $\left(M_{1}\right)$ e no manejo convencional $\left(M_{2}\right)$ em bananeira 'Prata anã'. Cristais Paulista - SP, 2004.

Ciênc. agrotec., Lavras, v. 31, n. 1, p. 35-40, jan./fev., 2007 

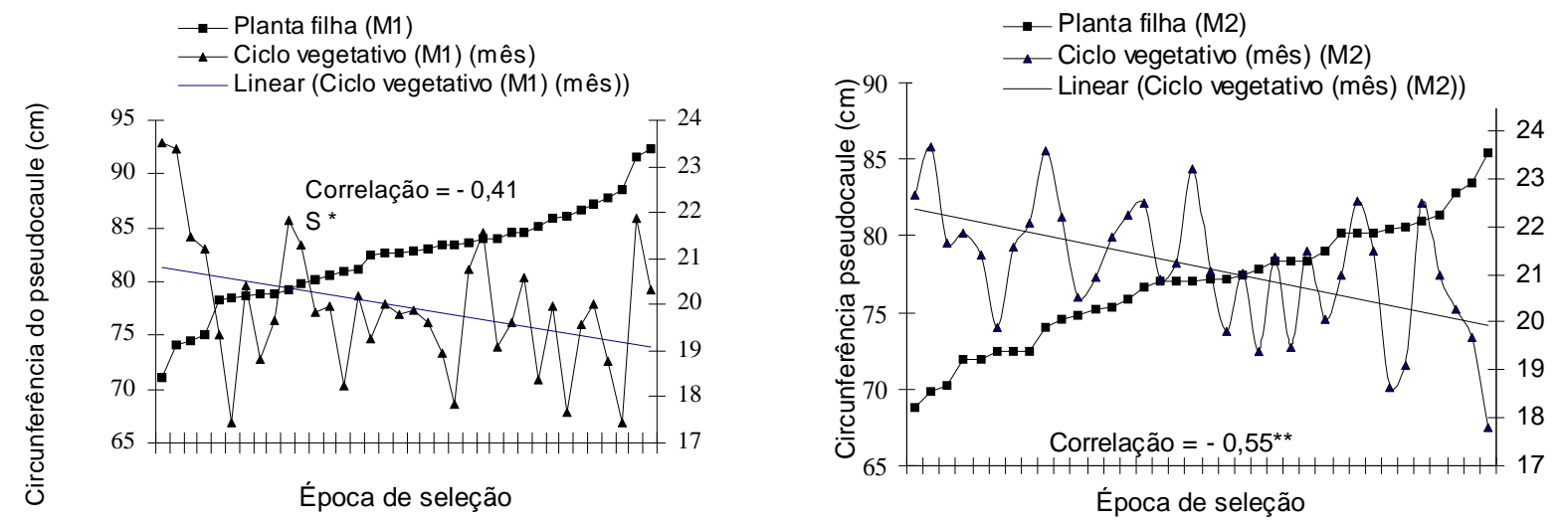

FIGURA 3 - Representação gráfica das correspondências entre as circunferências do pseudocaule das plantas-filha e seus respectivos ciclos vegetativos no manejo em que foi retirada a planta-mãe $\left(M_{1}\right)$ e no manejo convencional $\left(M_{2}\right)$ em bananeira 'Prata anã'. Cristais Paulista - SP, 2004.

\section{CONCLUSÕES}

De acordo com os estudos de correlação entre características morfológicas e produtivas da bananeira 'Prata-Anã' conclui-se que:

As circunferências dos pseudocaules entre plantamãe e da planta-filha correlacionam-se positivamente entre si;

A circunferência do pseudocaule da planta-mãe correlaciona-se positivamente com a sua produção, ao passo que para a planta-filha não há correlação entre estas características;

O ciclo vegetativo da planta-filha diminui à medida que aumenta a circunferência do seu pseudocaule (maior precocidade);

Não houve correlação entre os pesos dos cachos da planta-mãe e da planta-filha;

O manejo da touceira e a época de seleção da plantafilha não afetam as correlações entre as características morfológicas e produtivas entre planta-mãe e planta-filha.

\section{REFERÊNCIAS BIBLIOGRÁFICAS}

ALVES, E. J. (Org.). A cultura da banana: aspectos técnicos, sócio-econômicos e agro-industriais. 2. ed. Brasília, DF; Cruz das Almas: Embrapa-SPI, 1999. 585 p.

BELALCÁZAR-CARVAJAL, S. L. El cultivo de plátano en el trópico. Cáli: Feriva, 1991. 376 p.

BLOMME, G. A.; TENKOUANO, R.; SWENNEN, R. Relation entre les caractéristiques de croissance et le poids des régimes chez le bananier plantain (Musa spp. AAB).
MusaAfrica, [S.1.], v. 1, n. 1, 2003. Disponível em: <http:// wwww.inibap.org/network/musafrica fr.pdff) . Acesso em: 10 nov. 2004

BORGES, A. L. Solo, nutrição, calagem e adubação da bananeira. In: CURSO DE NUTRIÇÃO E ADUÇÃO DE FRUTEIRAS IRRIGADAS, 2., 2000, Petrolina. Resumos... Petrolina: Embrapa Semi-Árido, 2000. p. 1-29.

DEVALDENEBRO, J. J. Cosecha programada de banano. Augura, San José, v. 10, n. 2, p. 31-40, 1984.

FOOD AND AGRICULTURE ORGANIZATION OF THE UNITED NATIONS. Características fotossintéticas de grupos de cultivos de adaptabilidade climática. 1993. Disponível em: $i<\mathrm{http}: / /$ Www.fao.org/docrp.W $2962 \mathrm{~S} /$ w2962s06.hthis. Acesso em: 1 mar. 2004.

GOMES, J. A. Absorção de nutrientes pela bananeira cultivar "Prata Anã" (Musa ssp AAB, Subgrupo Prata) em diferentes estádios de desenvolvimento. 1988. $48 \mathrm{f}$. Tese (Doutorado) - Escola Superior de Agricultura "Luiz de Queiroz”, Universidade de São Paulo, Piracicaba, 1988.

LEDO, C. A. da S.; SILVA, S. de O.; REZENDE, J. C. F. de; RODRIGUES, M. G. V.; LIMA NETO, F. P.; JESUS, O. N. de. Estudo das relações entre caracteres da produção em cachos da bananeira 'Prata Anã' (Musa spp.). In: CONGRESSO BRASILEIRO DE FRUTICULTURA, 12., 2002, Belém. Anais... Belém: [s.n.], 2002. Disponível em: $\langle$ http://www.ufpel.tche.brsbfruti/anais xviicbf/fitotecnial 661.htm>. Acesso em: 10 ago. 2004. 
MANICA, I. Fruticultura tropical: banana. Porto Alegre: Cinco Continentes, 1997. 485 p.

MOREIRA, R. S. Banana: teoria e prática de cultivo. 2. ed. Campinas: Fundação Cargil, 1999.

SAS INSTITUTE. Statistical Analysis System: SAS/STAT guide for personal computers: statistics. 6. ed. Cary, 1988. $1028 \mathrm{p}$.

SENTELHAS, P. C.; PEREIRA, A. R.; ANGELOCCI, L. R. Meteorologia agrícola. 3. ed.Piracicaba: ESALQ, 2000. 172 p.
SIMMONDS, N. W. Bananas. 2. ed. London: Longmans, 1964. $512 \mathrm{p}$

SIQUEIRA, D. L. de. Variabilidade e correlações de caracteres em clones de bananeira 'Prata'. 1984. 66 f. Dissertação (Mestrado) - Escola Superior de Agricultura de Lavras, Lavras, 1984.

SOTO-BALLESTERO, M. Cultivo y comerialización del banano. 2. ed. Tibás: LIL, 1992. 649 p. 